What Do You (Think You) Need? Perceived vs. Experienced Effects of Need Fulfillment on Well-Being

Andreas B. Neubauer ${ }^{1,2}$, Veronika Lerche ${ }^{2}$, Friederike Koehler ${ }^{3}$, \& Andreas Voss ${ }^{2}$

${ }^{1}$ DIPF | Leibniz Institute for Research and Information in Education, and Center for Research on Individual Development and Adaptive Education of Children at Risk (IDeA), Frankfurt am Main, Germany

${ }^{2}$ Institute of Psychology, Heidelberg University, Heidelberg, Germany

${ }^{3}$ Institute of Medical Psychology at the Center for Psychosocial Medicine, University Hospital Heidelberg, Heidelberg, Germany

Correspondence should be addressed to Andreas B. Neubauer, Education and Human Development, DIPF | Leibniz Institute for Research and Information in Education, Frankfurt am Main, Germany. E-Mail: neubauer.andreas@dipf.de

Pre-registration: The reported study was not pre-registered.

Author contributions: ABN conceptualized this research, analyzed the data, and wrote the report; ABN, VL and FK designed the studies; VL and FK collected the data; all authors provided feedback and contributed to the revising and finalizing the paper, and approved the final version.

Declarations of interest: none.

Funding: Study 1 was supported by a grant from the German Research Foundation to Andreas Voss (Grant No. VO1288/2-1). 
This paper is not the copy of record and may not exactly replicate the final, authoritative version of the article. Please do not copy or cite without authors' permission. The final article will be available, upon publication, via its DOI: 10.1016/j.jrp.2020.103938 


\begin{abstract}
We compared two approaches towards assessing inter-individual differences in the effect of satisfaction and frustration of basic needs (autonomy, competence, relatedness) on wellbeing: perceived need effects (beliefs about the effect of need fulfillment on one's wellbeing) and experienced need effects (the within-person coupling of need fulfillment and wellbeing). In two studies (total $N=1,281$ ), participants reported perceived need effects in a multidimensional way. In Study 2, daily need fulfillment and affective well-being were additionally assessed (daily-diary study; ten days). Associations between perceived and experienced need effects were significant (albeit small) for all three frustration dimensions, but only for one satisfaction dimension (relatedness), suggesting that they capture different constructs and might be related to different outcomes.
\end{abstract}

Keywords: need strength; Self-Determination Theory; daily-diary study; affective wellbeing; ambulatory assessment 


\section{What Do You (Think You) Need? Perceived vs. Experienced Effects of Need Fulfillment on Well-Being}

\section{Introduction}

According to Self-Determination Theory (SDT; Deci \& Ryan, 2000; Ryan \& Deci, 2017), fulfillment of the basic psychological needs for autonomy, competence, and relatedness is a central requirement for well-being. Autonomy in the SDT framework is the perception of one's actions as voluntary and freely chosen. Competence refers to the experience of being effective in one's actions and to perceive a sense of mastery. Relatedness is defined as feeling a sense of belonging with other people, and to experience one's relationships as meaningful and shaped by reciprocity. It has been argued that it is important to distinguish the "bright side" (satisfaction) and "dark side" (frustration) of need fulfillment (Vansteenkiste \& Ryan, 2013). Previous research targeting this prediction has shown that need satisfaction and need frustration (the latter also sometimes referred to as need dissatisfaction) represent two largely independent dimensions of need fulfillment emphasizing the importance to distinguish the effects of need satisfaction and need frustration. Psychometric work showed that items capturing need satisfaction and items capturing need frustration load on separate, non-perfectly correlated factors (Chen et al., 2015; Neubauer \& Voss, 2018; Tóth-Király, Morin, Bőthe, Orosz, \& Rigó, 2017). Furthermore, need satisfaction and need frustration have been related to different predictors (e.g., need satisfaction primarily to autonomy supportive environments and need frustration primarily to controlling environments; Van der Kaap-Deeder, Vansteenkiste, Soenens, \& Mabbe, 2017) and outcomes (e.g., need satisfaction has been linked to life satisfaction and vitality, need frustration primarily to depression; Chen et al., 2015). Overall, there has been a vast amount of studies targeting the prediction of positive effects of need satisfaction and 
negative effects of need frustration on well-being, and most of this research has reported data consistent with this proposition (see Ryan \& Deci, 2017).

Whether or not there are meaningful inter-individual differences in the effects of need fulfillment is, however, a debated issue. A central tenet of SDT is its universality claim, proposing that fulfillment of the three basic psychological needs is associated with positive outcomes for all individuals. Hence, fulfillment of the needs for autonomy, competence, and relatedness is postulated to have positive consequences for all humans, regardless of culture, gender, or other person characteristics. Ryan, Soenens, and Vansteenkiste (2019) noted that this universality claim should, however, not be interpreted as stating that the positive effects are necessarily of equal size for all humans, but rather that differences in effects might be a matter of quantity, not quality. That is, while all humans are expected to reap benefits of the satisfaction of the needs for autonomy, competence, and relatedness (and to suffer from frustration of these three needs), they might do so to varying degrees.

SDT's universality claim has been targeted in a plethora of previous research. In the vast majority of these studies, inter-individual differences in the effects of need fulfillment on well-being have been challenged by examining potential moderators of this association. By and large, these studies yielded somewhat conflicting evidence regarding moderation effects. Whereas in many studies, inter-individual differences in, for example, culture (Chen et al., 2015), explicit motives (Sheldon \& Schüler, 2011) or need valuation (van Assche, Van der Kaap-Deeder, Audenaert, Schryver, \& Vansteenkiste, 2018) failed to exhibit moderating effects on the association of need fulfillment and well-being, other studies reported that this association is sometimes modulated by person-level variables such as gender (Bucher, Neubauer, Voss, \& Oetzbach, 2018) or implicit motives (Hofer \& Busch, 2011). Potentially, the presence and size of such moderation effects depend on a multitude of factors such as the 
outcome (general well-being vs. domain specific well-being; e.g., Schüler, Brandstätter, \& Sheldon, 2013) and, of course, on the type of the moderator.

With the present work, we add to the existing research a novel approach to examine inter-individual differences in the effect of need fulfillment on well-being. Specifically, we claim that two ways of assessing these inter-individual differences need to be distinguished: On the one hand, there are differences in perceived need effects that can be defined as the extent to which people think that need fulfillment will affect their well-being; on the other hand there are experienced need effects that are measured as the extent to which need fulfillment is actually associated with their well-being. Both of these measures are rooted in a within-person perspective on inter-individual differences in the effects of need fulfillment.

\subsection{The Benefits of a Within-Person Perspective}

There is growing awareness in the psychological literature that there is an important conceptual difference between between-person research questions and within-person research questions. Between-person research questions take the form of "Do individuals with a high level in measure $\mathrm{X}$ (i.e., a higher level than other individuals) also show higher levels in a measure Y?". Such questions can be addressed by correlations of variables on the betweenperson level and can be targeted in cross-sectional studies. Within-person research addresses questions like "Does an individual also have higher values on measure $\mathrm{Y}$ at times when values for measure X are higher than usual?" Questions like this cannot be answered by cross-sectional designs, because between-person associations are not necessarily equivalent to within-person associations (Brose, Voelkle, Lövdén, Lindenberger, \& Schmiedek, 2015; Hamaker, 2012; Molenaar, 2004; Voelkle, Brose, Schmiedek, \& Lindenberger, 2014). In order to address within-person associations, longitudinal data are required which are currently often collected in intensive longitudinal designs (such as daily diary studies, experience sampling studies or ambulatory assessment studies; see e.g. Mehl \& Conner, 2012). 
Within SDT, it is predicted that "fluctuations in need satisfaction will directly predict fluctuations in well-being" (Deci \& Ryan, 2000, p. 243), which emphasizes the importance of the within-person level for SDT's central predictions. There are several studies that have targeted the hypothesized association between need fulfillment and well-being using intensive longitudinal designs (e.g., Brenning, Soenens, Mabbe, \& Vansteenkiste, 2019; Neubauer \& Voss, 2018; Reis, Sheldon, Gable, Roscoe, \& Ryan, 2000), and results reported in these studies are largely in line with the prediction of a positive within-person association between need fulfillment and well-being: On days when participants report higher-than-usual need fulfillment they also report, for example, more positive mood (Neubauer \& Voss, 2018) and less negative affect (Reis et al., 2000).

Notably, intensive longitudinal designs allow examining not only the average withinperson effect, but also inter-individual differences in these effects (i.e., differences in experienced need effects). In the framework of multilevel models, inter-individual differences in the size of within-person effects of need fulfillment on well-being can be estimated, can be predicted by person-level characteristics, and they can be used as a predictor for future outcomes. Such an approach has been used in prior studies in the SDT framework. For example, in a recent study, Brenning et al. (2019) tested whether the size of the within-person association of daily need fulfillment and well-being in a sample of mothers depended on characteristics of the mother (self-criticism and dependency) or the child (various temperament dimensions). Findings showed that inter-individual differences in the withinperson association of daily need fulfillment and positive affect were associated with, for example, the child's extraversion (stronger association in mothers with less extraverted children). Neubauer, Lerche, and Voss (2018) examined the predictive validity of interindividual differences in the within-person association between need fulfillment and wellbeing. Findings from this study showed that participants differed in the degree to which daily 
satisfaction (frustration) of the needs for autonomy, competence, and relatedness was associated with better (worse) current mood. Inter-individual differences in the within-person association between fulfillment of the need for competence and mood predicted responses to a later experimental frustration of the need for competence: Those participants who had a larger effect of competence frustration, and a weaker effect of competence satisfaction on daily mood were most strongly affected by the experimental frustration.

In the present work we build on this prior research and examine inter-individual differences in the observed within-person association of satisfaction and frustration of the need for autonomy, competence, and relatedness with affective well-being using a daily-diary design. Operationalizing experienced need effects as the within-person coupling between daily need satisfaction/frustration and affective well-being allowed us to determine personspecific within-person effects of need fulfillment on well-being. While there is ample evidence that experienced need effects might be interesting from a conceptual perspective (e.g., as outcomes or predictors), obtaining these estimates in an intensive longitudinal design can be cumbersome and resource-intensive, especially since obtaining reliable estimates of couplings may require many observations per participant (Neubauer, Voelkle, Voss, \& Mertens, 2020). An important question, therefore, is whether similar information could be obtained from more economical assessments that do not require repeated assessments. To approach this question, we will compare experienced need effects to perceived need effects (the individuals' perception of how strongly they think their well-being is affected by need satisfaction/frustration). Comparing these two approaches is important since individuals may have a subjective view on the impact of need fulfillment on their well-being that does not perfectly align with the actual impact of need fulfillment.

\subsection{Associations between Perceived Need Effects and Experienced Need Effects}


Intuitively, one might expect the association between perceived need effects and experienced need effects to be rather strong, because individuals should know which experiences are associated with positive and negative affect for them, respectively. Conceptually, the mental representation of how strongly an individual thinks that their wellbeing is affected by occurrences in the environment (e.g., need fulfillment) should arise from experiences this individual has had in the past. For example, an individual who has observed that she feels very happy, joyful and enthusiastic when she experiences closeness with other people (and less happy, joyful and enthusiastic without such experiences of closeness) might infer that she profits to a great amount from experiences of relatedness satisfaction. However, we expect only moderate associations of perceived within-person effects and actual experiences. From a purely statistical perspective, in order to accurately infer the size of this association, an individual would have to (1) recall a representative sample of occasions when she experienced a lot vs. less of the predictor (e.g., instances when her need for relatedness was satisfied to varying degrees), (2) remember how happy, joyful and enthusiastic she felt during all of these occasions, and (3) estimate the association between predictor (relatedness satisfaction) and outcome (positive affect) based on the recalled occasions. Finally, she would need to (4) map this estimated association onto a response scale (e.g., respond to the question "when I feel close to other people, I feel particularly happy, joyful and enthusiastic" from "completely disagree" to "completely agree"). It is reasonable to assume that individuals do not perform these mental calculations when responding to items inquiring perceived need effects (or other within-person effects). Rather, they might use generalized beliefs about their behavior (based on identity-related beliefs; Robinson \& Clore, 2002) in such cases.

In the terminology used by Conner and Barrett (2012), perceived need effects are more likely to capture the believing self (“How do I think I am?”) than the experiencing self (“How am I?”). According to Conner and Barrett (2012), these two systems overlap but 
contain different information: Whereas the experiencing self is expected to be closely tied to physiological states, the believing self is often more predictive of deliberate decisions and future behavior. While prior work has examined the convergence / divergence between retrospective and momentary assessments of states (e.g., Broderick et al., 2008; Neubauer, Scott, Sliwinski, \& Smyth, 2019; Röcke, Hoppmann, \& Klumb, 2011), as well as their differential predictive validity (e.g., future behavior choices are often better predicted by indicators of the believing/remembering self than the experiencing self; Redelmeier, Katz, \& Kahneman, 2003; Wirtz, Kruger, Napa Scollon, \& Diener, 2003), little is known about the correspondence of the within-person association between a predictor (e.g., need frustration) and an outcome (e.g., negative affect), and people's beliefs about the relative size of this association. Research from the related domain of affective forecasting suggests that overall the prediction of the impact of a future event on one's well-being is often poor and prone to various biases (Wilson \& Gilbert, 2016). Perceived need effects combine elements of retrospective reports and affective forecasting: By asking individuals about the extent to which they think they respond to certain experiences, both retrospective episodic memory processes (remembering some situations and how one felt during these situations) and retrospective and prospective semantic memory processes (how they think they responded and how they think they will respond to these situations) will be engaged (see Robinson $\&$ Clore, 2002). These processes have been tied to the remembering/believing self (Conner \& Barrett, 2012) and are hypothesized to be (at least somewhat) discriminant from momentary experiences. Based on these considerations, it can be expected that there is some association between experienced need effects and perceived need effects, but that this association will be far from perfect.

\subsection{The Present Research}


The present paper addresses the measurement of inter-individual differences in the effects of need satisfaction vs. frustration on well-being. For this purpose, we differentiate between perceived and experienced effects. Specifically, the paper focuses on three research questions: First, we aimed to develop a questionnaire to assess inter-individual differences in the perceived effect of need satisfaction and frustration on well-being. This questionnaire goes beyond previous attempts in this area by directly assessing the perceived effect of need satisfaction and frustration on well-being. Second, we tested the factor structure of this questionnaire, examining whether participants differentiate between the three needs and/or satisfaction and frustration when reporting their perceived need effects. Based on prior studies emphasizing the importance of distinguishing need satisfaction and frustration we hypothesized that a six-factor model (three needs split into satisfaction and frustration dimensions) would provide good fit to the data. Third, we analyzed the association between perceived and experienced need effects. That is, we examined whether those individuals who believe that their well-being is particularly affected by satisfaction / frustration of a certain need would also show a stronger within-person association of need satisfaction / frustration and well-being when observed repeatedly with a daily-diary methodology. We had no strong expectations regarding the size of the association between perceived and experienced need effects, but we tentatively expected it to be small to medium.

Additionally, we explored the nomological net of the perceived need effect construct. Specifically, we investigated the correlations of perceived need effects with motives (Study 1), as well as personality traits (the Big Five), average need satisfaction / frustration, and life satisfaction (Study 2; see section 3 for hypotheses on personality traits). Implicit and explicit motives have been investigated as potential moderators of the association between need fulfillment and well-being, with mixed findings regarding their effect (e.g., Hofer \& Busch, 2011; Sheldon \& Schüler, 2011). Because implicit motives are often unrelated to explicit 
motives (with $r$ s $<.20$ reported in a meta-analysis; Köllner \& Schultheiss, 2014), and the latter should be more closely tied to the believing self, we tentatively expected stronger associations of perceived need effects with explicit than with implicit motives.

\section{Study 1}

In this study we tested the postulated six-factor structure of the newly developed measure for perceived need effects and examined correlations of this scale with implicit and explicit motives. Data and data analysis scripts can be found in the accompanying OSF repository (https://osf.io/ewhvs/?view_only=0742d6b4cca348d3945277e3cc30d154).

\subsection{Method}

\subsubsection{Sample and procedure}

Participants were pooled from two studies to increase power and precision in the estimation. Recruitment for both studies was very similar: The population was identical between studies (students at a large university in [blinded]) as was the study purpose (framed as a study on cognitive processes). Furthermore, the assessments occurred temporally close in time (between June and November 2015). In both studies, the relevant measures were administered on a computer screen. Sample 1 consisted of 128 participants $\left(M_{\text {age }}=22.9\right.$, $S D_{\text {age }}=4.98,77.3 \%$ female) who took part in a test-retest study. The study had the main aim of examining the reliability of the parameters of a mathematical model in an associative priming task (Study 2 in [blinded]). At both sessions, participants worked on the same response time task (the associative priming task). At the end of the first session, participants filled in three measures: an implicit motive measure, an explicit achievement motive measure, and the newly developed measure of perceived need effects. Sample 2 consisted of 52 participants $\left(M_{\text {age }}=21.0, S D_{\text {age }}=5.11,80.8 \%\right.$ female $)$ who worked on a color discrimination task with false performance feedback (unpublished data). Before working on 
the color discrimination task, participants of Sample 2 filled in the same three measures as Sample 1.

One participant was dropped for the present analyses because he did not vary in any of his responses to the questionnaire (he responded with "completely disagree" to all items), yielding a final sample of $N=179\left(M_{\text {age }}=22.3, S D_{\text {age }}=5.02,78.8 \%\right.$ female $) .{ }^{1}$

\subsubsection{Measures}

Several cognitive tests which are not relevant to the present research were administered in both samples. Only the relevant measures are reported below.

\subsubsection{Perceived need effects}

We developed a measure of perceived need effects by adjusting the German version (Neubauer \& Voss, 2016) of the Balanced Measure of Psychological Needs scale (BMPN; Sheldon \& Hilpert, 2012) in the following way: Instead of asking individuals to rate whether certain things had happened (e.g., "I took on and mastered hard challenges") we asked them to assess the estimated effect of these events on their well-being. Specifically, the instructions read as follows:

"People differ in what they need to feel happy. In the following you will find several statements about situations in which you might feel particularly good or bad. Please indicate for each statement to what degree it applies to you."

Items were formulated as contingency statements (e.g., "When I take on and master hard challenges, I feel particularly good."; "When I have a lot of pressure I could do without, I feel particularly bad."), and participants were instructed to rate each statement on a sevenpoint scale ranging from 1 ("completely disagree") to 7 ("completely agree"). Prior research on the BMPN suggests that this scale measures satisfaction and frustration of the three needs for autonomy, competence, and relatedness as separate constructs (Neubauer \& Voss, 2016;

\footnotetext{
${ }^{1}$ Rerunning the analyses using only the larger Sample 1 yielded essentially the same results.
} 
Sheldon \& Hilpert, 2012). For all satisfaction items we assessed whether this experience is associated with feeling particularly good (“...I feel particularly good”); for all frustration items we assessed whether this experience is associated with feeling particularly bad (“...I feel particularly bad"). Original German wording of all items along with an English translation can be found in the data dictionary in the OSF repository (https://osf.io/ewhvs/?view_only=0742d6b4cca348d3945277e3cc30d154).

\subsubsection{Implicit motives}

As implicit motive measure, we employed a short version of the Multi-Motive Grid (MMG; Schmalt, Sokolowski, \& Langens, 2010; Sokolowski, Schmalt, Langens, \& Puca, 2000). The MMG is a semi-projective measure which assesses the implicit motives for affiliation, achievement, and power in their hope and fear components. Participants are presented with a total of 14 pictures. Each picture goes along with a set of binary statements that describe motive-relevant thoughts and feelings. The participants must indicate whether or not the statements apply to the individuals shown in the pictures $(1=$ agree vs. $0=$ disagree $)$. Exemplary statements of the hope component are "Hoping to get in touch with other people" (affiliation motive), "Feeling confident to succeed at this task" (achievement motive), and "Trying to influence other people" (power motive). Exemplary statements of the fear component are "Being afraid of being rejected by others" (affiliation motive), "Thinking about lacking abilities at this task" (achievement motive), and "Anticipating to lose standing" (power motive). Each motive component is measured with two statements and each statement appears six times. Accordingly, motive component scores vary between 0 and 12 . Item order was constant for all participants (as instructed in the manual). Internal consistencies (Cronbach's $\alpha$ ) for the six subscales were $\alpha=.63$ (fear of failure), $\alpha=.69$ (hope of success), $\alpha=.70$ (fear of rejection), $\alpha=.62$ (hope of affiliation), $\alpha=.65$ (fear of power), and $\alpha=.70$ (hope of power). 


\subsubsection{Explicit motives}

We further measured the explicit achievement motive using the Achievement Motives Scale (AMS; Lang \& Fries, 2006). The AMS is composed of ten items, with half of them measuring the hope and fear component of the achievement motive, respectively. Participants were asked to rate their agreement with the items on a four-point Likert scale. Exemplary items are "I like situations, in which I can find out how capable I am" (hope) and "I am afraid of failing in somewhat difficult situations, when a lot depends on me“ (fear). Item order was randomized and was constant for all participants. Reliability in the present sample was $\alpha=$ .80 (fear of failure) and $\alpha=.70$ (hope of success).

\subsubsection{Data analysis}

We examined the factor structure of the 18 items assessing perceived need effects via confirmatory factor analyses (CFA). Specifically, we tested four models: (1) a one factor model (all items load on one common factor); (2) a two factor model (all items assessing satisfaction effects load on one factor; all items assessing frustration effects load on a different factor); (3) a three factor model (all items relating to one need load on one factor, regardless of whether they assess satisfaction effects or frustration effects); and (4) a six factor model (all items are split by need and satisfaction vs. frustration effect). We expected that the six factor model would yield the best fit to the data.

CFA were run using Mplus version 8.3. We used the robust maximum likelihood estimator (MLR) to account for potential deviations from a multivariate normal distribution of the indicators. Model fit was evaluated via the comparative fit index (CFI), the root mean square error of approximation (RMSEA), and the standardized root mean square residual (SRMR). We deemed model fit to be good (acceptable) when CFI $>.95$ (.90), RMSEA $<.06$ (.08), and SRMR < .06 (.08). Additionally, both the Akaike Information Criterion (AIC) and 
the Bayesian Information Criterion (BIC) are reported for relative model comparisons (smaller values in the information criteria indicate better model fit).

\subsection{Results}

\subsubsection{Factor structure}

Table 1 (upper panel) depicts the fit of the four competing models. As can be seen from these results, the six-factor model clearly provided the best fit of all models. In fact, absolute model fit indices (CFI, RMSEA, and SRMR) were not acceptable for the other three models. For the six factor model, fit indices indicated adequate (CFI, SRMR) to good (RMSEA) fit. Hence, for further analyses, we assume that the 18 items are best represented by six correlated factors. Standardized factor loadings, factor variances and intercorrelations can be found in the Supplemental Online Material (Table S1).

\subsubsection{Descriptive statistics and correlations}

Figure 1 (left panel) depicts the distribution of the six scale means and bivariate scatterplots. As can be seen from this figure, the range of the satisfaction effect subscales was restricted, with all individuals reporting scores of 3.67 or higher (on a scale with a possible range from 1 to 7). Hence, differences in the perceived impact of positive experiences on positive affect seemed to be comparatively small: Virtually all participants indicated strong positive responses to need satisfaction. The variance of need frustration effects appeared to be larger: Whereas the average participant in the sample would expect to feel rather bad when encountering need frustration (means between 4.97 and 5.69 for the three needs), there were also some individuals who reported a moderate to low perceived association between need frustration and well-being (minimum between 1.33 for autonomy and relatedness and 1.67 for competence).

Correlations of the six scale scores with the implicit and explicit motives are shown in Table 2 (upper panel). Perceived need effects were largely uncorrelated with both motive 
types. An exception was the correlation between perceived competence frustration effect and explicit fear of failure which amounted to .53 .

\subsection{Discussion}

Of the four measurement models, a six factor structure clearly showed the best model fit. This suggests that participants differentiate the effects of satisfaction and frustration, and further differentiate between the effects of fulfillment of the three needs. Descriptive statistics showed a restricted range of need satisfaction effects whereas need frustration effects covered more or less the entire theoretically possible range of the scale. This indicates that differences in the (perceived) effect of need frustration might be larger or better integrated in individuals' self-concepts than differences in the effect of need satisfaction. Correlations of perceived need effects with implicit motives were small and largely non-significant. In the Study 2, we aimed to investigate whether perceived need effects are associated with the experienced within-person effect of need satisfaction and frustration on well-being.

\section{$3 \quad$ Study 2}

Because we did not expect the associations between experienced need effects and perceived need effects to be large, we tested them in a large sample $(N>1,000)$ which should provide sufficient statistical power even for small to medium sized effects. Furthermore, we investigated the nomological net around the perceived need effect construct by examining associations with different constructs: the Big Five personality traits and life satisfaction. The latter was included to explore whether high perceived associations between need satisfaction and well-being might be related to an overall positive impression of one's life circumstances. With regard to the Big Five, we tentatively expected that Neuroticism would be linked to perceived need frustration effects (for all three needs), given the overlap between Neuroticism and tendencies to respond more strongly to negative experiences (e.g., Bolger \& Schilling, 1991). Furthermore, it might be expected that highly extraverted and highly 
agreeable individuals would expect to profit to a large extent from positive relationship experiences. Hence, positive correlations between Extraversion and Agreeableness with perceived relatedness satisfaction effect were expected. Further, previous research has suggested that Conscientiousness is linked to experiences of competence fulfillment (Church et al., 2013). A potential explanation of this link is that highly conscientious individuals derive particularly strong pleasure from feelings of competence satisfaction and therefore seek after situations in which they can experience competence satisfaction more often. Hence, Conscientiousness might be positively associated with perceived competence satisfaction effect. Associations with Openness were examined in an exploratory fashion.

\subsection{Method}

\subsubsection{Sample and procedure}

We used data from a study that examined [blinded]. ${ }^{2}$ For this study, hobby musicians were recruited by contacting hobby and university orchestras, choirs and bands in Germany. These groups were asked to distribute the invitation for study participation among their members by sending an e-mail or handing out the printed version of the invitation.

Furthermore, the invitation was posted in different musician forums. Interested individuals could sign up for the study by contacting the research team via e-mail, upon which they received detailed information on the study procedure. Participants then received a link to an online questionnaire (the baseline assessment) and they were asked to fill in the questionnaire until a predetermined date. Seven days after this date, the second part of the study started, which comprised daily assessments via online questionnaires. For ten consecutive days, participants received an e-mail at $7 \mathrm{pm}$ each day, which contained the link to the daily

\footnotetext{
${ }^{2}$ Results from this study are also reported in [blinded]. There is some overlap between the results reported here and the results reported by [blinded] and the results on the main effects of daily need satisfaction / frustration on well-being are not original to the present study (these results are therefore not reported here). However, the results regarding inter-individual differences in perceived and experienced need effects have not been reported previously and are original results of the present work.
} 
survey; each survey took about 5 to 10 minutes to complete. Participants were asked to complete the survey before going to bed on the same day. The link was deactivated at 6 am. A total of 1,193 participants started the baseline assessment. Only those participants who filled in the questionnaire assessing perceived need effects and completed at least one of the daily assessments were retained for further analyses, resulting in a final sample of $N=1,102$ participants $\left(M_{a g e}=39.81, S D_{a g e}=17.62,65.5 \%\right.$ female $)$. On average, participants completed 7.80 (out of 10$)$ daily assessments $\left(M_{\text {compliance }}=78.0 \%, S D_{\text {compliance }}=25.3 \% ; M d n_{\text {compliance }}=\right.$ $90 \%)$.

\subsubsection{Measures}

Both in the baseline assessment and in the daily assessments, a number of constructs not relevant for the present study were assessed; only the relevant constructs are listed below (data and analysis scripts can also be found in the OSF repository).

\subsubsection{Perceived need effects}

Perceived need effects were assessed during the baseline assessment. We used the same 18 items to assess perceived need effects as in Study 1. Again, for each item participants indicated the degree to which they agree with the respective statement on a scale from 1 (“completely disagree") to 7 (“completely agree").

\subsubsection{Personality}

The Big Five personality traits (Extraversion, Neuroticism, Agreeableness, Conscientiousness, and Openness) were measured at the baseline assessment using a German Short Form of the Big Five Inventory (Rammstedt \& John, 2005). In this scale, each personality trait is assessed using four items (with the exception of Openness which is assessed by five items). Participants were instructed to indicate the extent to which the statements describe them on a scale ranging from 1 ("does not describe me at all") to 5 ("describes me very well"). Internal consistencies for the five scales in this study were $\alpha=$ 
.83 (Extraversion), $\alpha=.74$ (Neuroticism), $\alpha=.66$ (Agreeableness), $\alpha=.71$

(Conscientiousness), and $\alpha=.68$ (Openness).

\subsubsection{Life satisfaction}

We used the German translation (Glaesmer, Grande, Braehler, \& Roth, 2011) of the Satisfaction with Life Scale (SWLS; Diener, Emmons, Larsen, \& Griffin, 1985) to assess life satisfaction at the baseline assessment. Participants were presented with five statements and asked to report the degree to which they agree with each of these statements on a scale ranging from 1 ("completely disagree") to 7 (“completely agree"). Internal consistency was $\alpha$ $=.86$ in the present sample.

\subsubsection{Daily need fulfillment}

On each of the ten days in the daily assessment part of the study, participants were asked to report their daily satisfaction and frustration of the needs for autonomy, competence, and relatedness. We used the daily-diary version of the German BMPN (Neubauer \& Voss, 2018). As suggested in this previous work, we replaced the item "I was lonely" by "I was excluded or ostracized" (see also Neubauer \& Voss, 2016). Participants were asked to rate to what degree each of 18 statements (e.g., "Today, I was really doing what interests me.”) applied to them with respect to the present day on a scale ranging from 1 ("not at all") to 7 ("completely"). Reliability of the six scales was estimated separately for the within-person level and the between-person level using multilevel Cronbach's $\alpha$ (see Geldhof, Preacher, \& Zyphur, 2014). The estimates on the between-person level (autonomy satisfaction: $\alpha=.85$; competence satisfaction: $\alpha=.94$; relatedness satisfaction: $\alpha=.97$; autonomy frustration: $\alpha=$ .86 ; competence frustration: $\alpha=.91$; relatedness frustration: $\alpha=.91$ ) were somewhat higher than their counterparts on the within-person level (autonomy satisfaction: $\alpha=.67$; competence satisfaction: $\alpha=.78$; relatedness satisfaction: $\alpha=.83$; autonomy frustration: $\alpha=$ .64 ; competence frustration: $\alpha=.65$; relatedness frustration: $\alpha=.65$ ). 


\subsubsection{Daily affect}

Affect was assessed using the German version (Krohne, Egloff, Kohlmann, \& Tausch, 1996) of the Short Form of the Positive and Negative Affect Schedule (Thompson, 2007). Positive affect (PA) was assessed using five items (active; determined; attentive; inspired; alert) as was negative affect (NA: afraid; nervous; upset; hostile; ashamed). Participants were asked how intensively they had experienced each affective state during the day on a scale ranging from 1 ("very slightly") to 5 ("extremely"). Internal consistencies were good at the between-person level (PA: $\alpha=.92$; NA: $\alpha=.88$ ) and somewhat lower at the within-person level (PA: $\alpha=.81 ;$ NA: $\alpha=.64)$.

\subsubsection{Data analyses}

In a first step, we again tested the factor structure of the 18 perceived need effect items with CFA. The same models (one factor model; two factor model; three factor model; six factor model) as in Study 1 were tested; based on results in Study 1, we expected the six factor model to yield the best fit. Next, we examined the associations of the perceived need effect scales with personality, life satisfaction, as well as mean affect and need fulfillment (aggregated across all days in the daily-diary part).

To investigate the correspondence between perceived need effects and experienced need effects, we conducted multilevel model analyses. Multilevel modeling was chosen as data analytic framework to account for the nested data structure, with daily observations (Level 1) nested within participants (Level 2). All models were analyzed following the same structure: Person $i$ 's score on the dependent variable at day $t\left(Y_{i t}\right.$; depending on the model this was either NA or PA) was predicted by this person's score on a predictor $X_{i t}$ (one of the six daily need fulfillment scales). The predictor was centered on the person mean. Hence, positive (negative) values on $X_{i t}$ represent days on which this variable was larger (smaller) than on average for this individual. Therefore, positive values on $X_{i t}$ cannot be interpreted as 
a high literal value on $\mathrm{X}$, but rather as a higher-than-usual value on $\mathrm{X}$ (see e.g., Hofstee \& $\tan$ Berge, 2004). This centering strategy is necessary to obtain the pure within-person effect of $X_{i t}$ on $Y_{i t}$ (Wang \& Maxwell, 2015). Further, we modeled a random slope for the effect of $X_{i t}$ on $Y_{i t}$, thus allowing the size of within-person effects to vary across participants. We further added a person level variable $\left(M_{i}\right.$; this was one of the six perceived need effect scales centered on the grand mean) into the model. This variable was used to predict participant $i$ 's intercept in $Y_{i t}\left(\beta_{0 i}\right)$ and participant $i$ 's within-person effect of $X_{i t}$ on $Y_{i t}\left(\beta_{1 i}\right)$ :

Level 1:

$$
Y_{i t}=\beta_{0 i}+\beta_{1 i} \cdot X_{i t}+\varepsilon_{i t}
$$

Level 2:

$$
\begin{aligned}
& \beta_{0 i}=\gamma_{00}+\gamma_{01} \cdot M_{i}+v_{0 i} \\
& \beta_{1 i}=\gamma_{10}+\gamma_{11} \cdot M_{i}+v_{1 i}
\end{aligned}
$$

A significant interaction effect $\left(\gamma_{11}\right)$ would indicate that the size of the within-person effect of $X_{i t}$ depends on $M_{i}$.

For example, in one model, we predicted positive affect $\left(Y_{i t}\right)$ from daily autonomy satisfaction $\left(X_{i t}\right)$ and from the perceived autonomy satisfaction effect $\left(M_{i}\right)$. A significant positive interaction in this model would indicate that those individuals who believe that their well-being is more strongly positively affected by autonomy satisfaction (= higher perceived autonomy satisfaction effect) show a larger within-person association of autonomy satisfaction and PA in their daily lives (= experienced autonomy satisfaction effect). A total of 36 models (six daily need fulfillment scales $\times$ six perceived need effects) were estimated using the nlme package (Pinheiro, Bates, DebRoy, Sarkar, \& R Development Core Team, 2018) in R. Of these 36 models, we considered only those six interaction effects to be of crucial interest in which the perceived need effect corresponded to the daily need fulfillment scale (e.g., perceived autonomy satisfaction effect moderating the effect of daily autonomy 
satisfaction, but not perceived autonomy satisfaction effect moderating the effect of the other five daily need fulfillment scales). The results of these six models will therefore be reported as primary analyses. For sake of completeness, we will also report the cross-level interactions of the 30 other models, but we note that these should be considered exploratory.

\subsection{Results and Discussion}

\subsubsection{Factor structure}

Comparing the four competing measurement models showed that, as in Study 1, the best fit was obtained for the six factor model $(\mathrm{CFI}=.941, \mathrm{RMSEA}=.047, \mathrm{SRMR}=.041$; see Table 1, lower panel). The pattern of factor loadings, factor variances and correlations among the factors was very similar to Study 1 (see Supplemental Online Material, Table S1).

\subsubsection{Descriptive statistics and correlations}

Distributions of the six scale means and bivariate scatterplots are depicted in Figure 1 (right panel). These results are highly comparable to the results in Study 1 and show that perceived need satisfaction effects have a restricted range, even in this large and heterogeneous sample. Table 2 (lower panel) reports the bivariate correlations of the six perceived need effect scales with the Big Five personality traits, life satisfaction, as well as mean levels of PA, NA, and the six need fulfillment scales aggregated from the daily-diary part of the study. Most of these correlations were small, but the structure of these associations was consistent: Participants who think that their well-being is strongly positively affected by need satisfaction tend to be more extraverted, more conscientious, and more open for new experiences. Furthermore, they are more satisfied with their lives, and reported higher PA and lower NA, as well as higher need satisfaction in their daily lives. The correlation pattern of need frustration effects was somewhat different: Participants who think that their well-being is strongly negatively affected by need frustration reported lower Extraversion and higher 
Neuroticism. Higher perceived need frustration effects were further associated with lower life satisfaction, as well as lower PA, higher NA, and higher average need frustration in daily life.

\subsubsection{Associations between perceived need effects and experienced need effects}

Table 3 depicts the cross-level interaction effects between daily need satisfaction / frustration and perceived need effects predicting daily PA and NA. Results show that all three perceived need frustration effects moderated the within-person association between the corresponding daily need frustration and NA. In contrast, of the three perceived need satisfaction effects, only perceived relatedness satisfaction effect moderated the withinperson association between the corresponding daily need satisfaction and $\mathrm{PA}, b=.031, p=$ .009. These results indicate that, for example, participants who perceived stronger effects of relatedness frustration on well-being (i.e., participants who think that they feel particularly bad when they encounter relatedness frustration) exhibit a stronger association between relatedness frustration and NA in their day-to-day lives. Hence, these four statistically significant and positive interaction effects are in line with the assumption that perceived need effects and experienced need effects converge.

To quantify the size of the interaction effect, we computed a measure of pseudo- $R^{2}$ to estimate the amount of random slope variance that is accounted for by the cross-level interaction (by comparing the random slope variance in these models to the random slope variance in models without the cross-level interaction). The effect sizes for the cross-level interactions are also reported in Table 3. As can be seen from these estimates, the amount of variance in experienced need effects explained by perceived need effects was rather small $(<3 \%)$. Figure 2 shows the estimated within-person effects of need satisfaction on PA (upper panel) and need frustration on NA (lower panel). To illustrate the impact of perceived need effects, we split the sample into tertials according to their respective perceived need effect. 
The figure shows that (a) there is heterogeneity in the within-person association between need fulfillment and well-being (the individual grey lines are not perfectly parallel); (b) these differences are largely a matter of gradation (most of these lines are ascending, indicating a positive within-person effect); and (c) perceived need effects do not explain a large portion of inter-individual differences in this association (within a row the slope of the red line does not change much from the left to the right column).

\subsubsection{Exploratory analyses}

In further analyses, we also examined whether perceived need effects moderated the effects of other need fulfillment dimensions on affective well-being. Results of these 30 models can be found in the Supplemental Online Material (Table S2). Please note that, given the exploratory nature of these analyses as well as the large sample size, we do not report $p$ values for these associations but rather interpret their estimated effect size. These analyses revealed no large associations of experienced need satisfaction effects with any (noncorresponding) perceived need effects, pseudo- $R^{2}<1.5 \%$ for all. Inspection of the effect of perceived need frustration effects on (non-corresponding) experienced need effects revealed cross-effects in particular for perceived competence frustration effect: Those participants who think that their well-being is particularly strongly affected by competence frustration not only showed a stronger association between daily competence frustration and NA (see Table 3), but also a stronger association between the frustration of the other two needs and NA (Table S2).

\section{General Discussion}

Fulfillment of the basic psychological needs for autonomy, competence, and relatedness has been shown to be associated with higher levels of well-being in previous research (see Ryan \& Deci, 2017). Inter-individual differences in the effect of need fulfillment on well-being have gained some attention in studies employing intensive 
longitudinal designs. In this study, we aimed to investigate the possibility to assess these inter-individual differences via a self-report measure capturing perceived need effects (individuals' beliefs about the effects of need fulfillment on their own well-being). Specifically, we investigated the structure and correlates of these beliefs and the correspondence of these beliefs with individuals' within-person associations between need fulfillment and well-being (experienced need effects).

\subsection{Perceived Need Effects: Structure and Correlates}

When asked to indicate whether they think that their well-being is particularly affected by satisfaction and frustration of the needs for autonomy, competence and relatedness, individuals differed in their responses. On the most general level, this indicates that people do not think that fulfillment of these three needs is equally important for their well-being. Three findings from our studies were particularly noteworthy: First, in their assessment of what makes them feel particularly good or bad, individuals differentiated between the three needs. This means that these self-assessments are not pure reflections of a halo effect, but rather indicative of the necessity to differentiate between the three needs postulated by SDT. Second, within each need individuals distinguished between the perceived effects of need satisfaction and need frustration. This emphasizes the importance to distinguish the "bright side" and the "dark side" of need fulfillment (Vansteenkiste \& Ryan, 2013) also when it comes to investigating inter-individual differences in the effects of need fulfillment. Third, the variance in the perceived effects of need satisfaction was restricted. In total between $55.0 \%$ (competence) and $95.1 \%$ (relatedness) of our 1,281 participants responded above the scale midpoint in the perceived need satisfaction effects. Hence, there seem to be only small differences in the extent to which humans believe that their well-being is affected by need satisfaction. This finding testifies to SDT's universality assumption and to the assumption that these psychological needs are fundamental in nature (see also Sheldon, 
Elliot, Kim, \& Kasser, 2001). On the other hand, there were larger inter-individual differences in perceived need frustration effects: People differ in the extent to which they think that their well-being is impacted by the frustration of a basic psychological need.

We started to explore the nomological net of the construct of perceived need effects by investigating its association with other trait measures. Overall, most of these associations were only small and indicate discriminant validity of perceived need effects with regard to implicit motives, the explicit achievement motive, the Big Five personality traits, life satisfaction, as well as average affective well-being and need fulfillment in participants' daily lives. The correlations with the Big Five personality traits were consistent with the content of the perceived need effects and with our tentative expectations: extraverted and agreeable persons believed that their well-being was more strongly affected by relatedness satisfaction. Conscientiousness was associated with stronger perceived effects of competence satisfaction. Neuroticism was related with the perceived effects of frustration of all three needs. Finally, Openness was associated with all three perceived need satisfaction effects, with the descriptively largest association with autonomy satisfaction effect. We note that this correlation pattern was not distinct (e.g., Conscientiousness was also associated with the perceived effects of satisfaction of the other two needs). Nevertheless, we interpret the overall pattern of these correlations as support for the construct validity of the assessment of perceived need effects.

The correlation pattern between perceived need effects and motive measures is particularly interesting for studies attempting to integrate SDT with motive disposition theory (MDT; McClelland, 1985). Recently, Schüler, Baumann, Chasiotis, Bender, and Baum (2019) emphasized that one of the areas of divergence between SDT and MDT is that in SDT, there is no counterpart to the distinction between explicit motives and implicit motives which is central to MDT. In our view, perceived need effects and experienced need effects as 
operationalized in the present work might fill this gap. Implicit motives are assumed to predict the affective response in motive relevant situations (see Brunstein, 2018).

Experienced need effects in the present study were operationalized as the affective correlates of need satisfaction and frustration in daily life, hence directly corresponding to a core characteristic of implicit motives. In the motive literature it has been reported that implicit and explicit motives are only weakly correlated (Köllner \& Schultheiss, 2014). In the present work, perceived need effects were largely uncorrelated with implicit motives, but there was a substantial overlap between the explicit need for achievement (fear of failure) and perceived competence frustration effects.

We note, however, that the correspondence between explicit motives and perceived need effects was only observed for the fear component of the motive and the frustration component of the perceived need effect, respectively. The correlation between explicit hope for success and perceived competence satisfaction effect was rather low $(r=.15)$ and not statistically significant. Whether this can be attributed to the restricted variance of the perceived satisfaction effect or is indicative of a generally weaker association between the hope component of the motive and perceived need satisfaction effects (vs. fear components and need dissatisfaction effects), and whether a similar pattern can be observed for correspondence between explicit motives and perceived need effects for the needs for autonomy and relatedness as well will need to be determined in future research. Furthermore, we cannot directly address the possibility if experienced need effects are the SDT counterpart of implicit motives because we did not assess implicit motives in Study 2. However, in prior work (Neubauer et al., 2018), there was no strong association between the implicit need for achievement and experienced need effects. This might suggest that the divergence between SDT and MDT goes beyond the lack of an implicit measure in SDT (or some other distinctions mentioned by Schüler et al., 2019), but might rather indicate that differences 
between these two theories are too large to be bridged by an integrative attempt (as speculated by Ryan et al., 2019). At this stage, this remains an open question and requires further research targeting the potential overlap and divergence between these two theoretical accounts. Investigating both perceived need effects and experienced need effects in this realm can be highly informative, and we hope that researchers consider both of these approaches in future studies.

In summary, the present findings suggest that individuals perceive the importance of need satisfaction and frustration for their well-being in a differentiated way. These differences are related to inter-individual differences in personality and explicit motives in a theoretically plausible fashion.

\subsection{Divergence of Perceived and Experienced Need Effects: Know Thy Needs?}

Our research revealed only small associations between perceived need effects and experienced need effects. That is, those individuals who reported that their well-being was particularly strongly affected by, for example, competence satisfaction did not necessarily exhibit a stronger within-person association between day-to-day fluctuations in competence satisfaction and positive affect. While there was some correspondence (at least for the frustration dimensions of need fulfillment), the associations were weak and not discriminant: In fact, the strongest association between perceived and experienced need effects was obtained for perceived competence frustration effect and experienced autonomy frustration effect.

Explicit self-report assessments of perceived need effects are affected by multiple processes, all of which might explain the divergences to experienced need effects reported in the present work. For example, both retrospective memory processes and semantic memory processes likely play an important role when individuals are asked about their perceived responses to need fulfillment (see Robinson \& Clore, 2002). However, not only distorted 
memories of one's past, but also biased expectations about the effect of future events on one's affect might be a source of this divergence. There is some evidence suggesting that individuals overestimate the impact of both positive and negative events on their well-being, which might be caused by various cognitive biases (e.g., overestimation of the duration of the impact of an event and overly strong focus on single events; Wilson \& Gilbert, 2016). Our findings showed that most of our participants reported perceived need effects (in particular: need satisfaction effects) above the scale midpoint. This could indicate that participants (on average) overestimate the impact of need satisfaction on well-being. However, if all individuals overestimated these effects to the same extent, this should result in more or less perfect convergence between perceived and experienced need effects (since the participants' rank order in perceived and experienced need effects would be preserved). Therefore, a general overestimation of anticipated affective responses cannot explain the rather low convergence.

Another explanation of these divergences might be that perceived and experienced need effects represent somewhat distinct concepts since they are related to different selves: Experienced need effects represent the experiencing self (Conner \& Barrett, 2012) in the form of "if...then...profiles" (Mischel, Shoda, \& Mendoza-Denton, 2002). Depending on the temporal resolution at which they are assessed, they represent indicators of everyday dynamics among inputs (if: need fulfillment) and outputs (then: well-being) and might thereby capture "life as it is lived" (Bolger, Davis, \& Rafaeli, 2003). Perceived need effects on the other hand represent the believing self (Conner \& Barrett, 2012): Self-reports of how individuals think they respond are probably influenced by how they actually respond, but they are also affected by general beliefs about oneself. Such beliefs might be persistent, and somewhat resistant to change, and (compared to actual experiences) more predictive of deliberate future choices. These considerations lead to interesting questions for future 
research that might shed more light onto the divergence of experienced and perceived need effects. Specifically, future studies might investigate the underlying mechanisms of this divergence (Do they diverge because they tap different "selves" and/or because they rely on differential contributions of semantic and episodic memory process? Are they caused by affective forecasting errors or erroneous memories of one's past experiences?), explore interindividual differences in convergence (Is the association between perceived and experienced need effects stronger for some individuals than for others? Is the degree of convergence adaptive for mental health or other outcomes?), and examine their differential predictive validity for future outcomes.

\subsection{Limitations and Conclusions}

The present research comes with a number of limitations. First, only a selective sample of constructs was assessed in the two studies. It would be interesting to further explore the nomological net of perceived need effects in future studies. For example, explicit motives (in addition to the achievement motive), need valuation and need desire (Chen et al., 2015) seem to be interesting candidates to further explore the convergent and discriminant validity of these measures. Second, we interpret the relative independence of perceived and experienced need effects as indicating that they might capture different aspects of the self (remembering/believing self vs. experiencing self; Conner \& Barrett, 2012). Future research is needed to specifically test this proposition. For example, perceived and experienced need effects could be used as predictors of intended future behavior and automated responses. Based on our interpretation, we would expect that perceived need effects would be a better predictor of deliberate future behavior, whereas experienced need effects would more strongly predict automated responses (e.g., the affective or physiological response in a need relevant situation; see Neubauer et al., 2018, for data in line with this prediction). In this context, it would also be highly informative to include additional outcomes beyond self- 
reports (e.g., physiological measures, objective behavior, or implicit measures of personality). Third, while sample size on the person level was large in Study 2, the rather short observation period of ten days might not have been sufficient to obtain a representative sample of our study participants' daily lives. Increasing the number of observations per day might be crucial to increase the reliability of the assessment of experienced need effects (Neubauer et al., 2020). Additionally, internal consistencies of perceived need effects (in particular perceived autonomy effects) were all .80 or lower. This might have led to an attenuated estimation of their association with experienced need effects. Fourth, the two samples investigated in the present work (Study 1: 79\% female participants and students; Study 2: hobby musicians) are not representative of the general population. It remains to be determined to what extent the reported findings can be generalized to other samples.

In conclusion, the present research shows that assessing inter-individual differences in the effects of need fulfillment on well-being via trait self-reports yields different results compared to their assessment as experienced need effects in an intensive longitudinal design. Our findings show that inter-individual differences in the perceived effect of need fulfillment on well-being can be represented as a six-dimensional construct, emphasizing the necessity to distinguish between the needs for autonomy, competence, and relatedness on the one hand, and between need satisfaction and need frustration on the other hand. Perceived need effects showed weak associations with experienced need effects only for the need frustration scales and for one satisfaction scale, which might suggest that they capture distinct constructs and might be differentially related to other variables. Furthermore, inter-individual differences in the effect of need fulfillment on well-being were primarily of quantitative nature, suggesting that virtually all individuals profit from need satisfaction and suffer from need frustration, but to varying degrees. 


\section{References}

Bolger, N., \& Schilling, E. A. (1991). Personality and the problems of everyday life: The role of neuroticism in exposure and reactivity to daily stressors. Journal of Personality, 59, 355-386. https://doi.org/10.1111/j.1467-6494.1991.tb00253.x

Bolger, N., Davis, A., \& Rafaeli, E. (2003). Diary methods: Capturing life as it is lived. Annual Review of Psychology, 54, 579-616. https://doi.org/10.1146/annurev.psych.54.101601.145030

Brenning, K., Soenens, B., Mabbe, E., \& Vansteenkiste, M. (2019). Ups and downs in the joy of motherhood: Maternal well-being as a function of psychological needs, personality, and infant temperament. Journal of Happiness Studies, 20, 229-250. https://doi.org/10.1007/s10902-017-9936-0

Broderick, J. E., Schwartz, J. E., Vikingstad, G., Pribbernow, M., Grossman, S., \& Stone, A. A. (2008). The accuracy of pain and fatigue items across different reporting periods. Pain, 139, 146-157. https://doi.org/10.1016/j.pain.2008.03.024

Brose, A., Voelkle, M. C., Lövdén, M., Lindenberger, U., \& Schmiedek, F. (2015).

Differences in the between-person and within-person structures of affect are a matter of degree. European Journal of Personality, 29, 55-71. https://doi.org/10.1002/per.1961

Brunstein, J. C. (2018). Implicit and explicit motives. In J. Heckhausen \& H. Heckhausen (Eds.), Motivation and Action (pp. 369-405). Cham: Springer International Publishing. https://doi.org/10.1007/978-3-319-65094-4_9

Bucher, A., Neubauer, A. B., Voss, A., \& Oetzbach, C. (2018). Together is better: Higher committed relationships increase life satisfaction and reduce loneliness. Journal of Happiness Studies, 35, 674. https://doi.org/10.1007/s10902-018-0057-1

Chen, B., Vansteenkiste, M., Beyers, W., Boone, L., Deci, E. L., Van der Kaap-Deeder, J., . . Verstuyf, J. (2015). Basic psychological need satisfaction, need frustration, and 
need strength across four cultures. Motivation and Emotion, 39, 216-236.

https://doi.org/10.1007/s11031-014-9450-1

Church, T. A., Katigbak, M. S., Ching, C. M., Zhang, H., Shen, J., Arias, R. M., . . Alvarez, J. M. (2013). Within-individual variability in self-concepts and personality states: Applying density distribution and situation-behavior approaches across cultures. Journal of Research in Personality, 47, 922-935. https://doi.org/10.1016/j.jrp.2013.09.002

Conner, T. S., \& Barrett, L. F. (2012). Trends in ambulatory self-report: The role of momentary experience in psychosomatic medicine. Psychosomatic Medicine, 74, 327337. https://doi.org/10.1097/PSY.0b013e3182546f18

Deci, E. L., \& Ryan, R. M. (2000). The "What" and "Why" of goal pursuits: Human needs and the Self-Determination of behavior. Psychological Inquiry, 11, 227-268. https://doi.org/10.1207/S15327965PLI1104_01

Diener, E., Emmons, R. A., Larsen, R. J., \& Griffin, S. (1985). The Satisfaction With Life Scale. Journal of Personality Assessment, 49, 71-75. https://doi.org/10.1207/s15327752jpa4901_13

Geldhof, G. J., Preacher, K. J., \& Zyphur, M. J. (2014). Reliability estimation in a multilevel confirmatory factor analysis framework. Psychological Methods, 19, 72-91. https://doi.org/10.1037/a0032138

Glaesmer, H., Grande, G., Braehler, E., \& Roth, M. (2011). The German version of the Satisfaction With Life Scale (SWLS). European Journal of Psychological Assessment, 27, 127-132. https://doi.org/10.1027/1015-5759/a000058

Hamaker, E. L. (2012). Why researchers should think "within-person". A paradigmatic rationale. In M. R. Mehl \& T. S. Conner (Eds.), Handbook of research methods for studying daily life (pp. 43-61). New York: Guilford Press. 
Hofer, J., \& Busch, H. (2011). Satisfying one's needs for competence and relatedness: consequent domain-specific well-being depends on strength of implicit motives. Personality \& Social Psychology Bulletin, 37, 1147-1158. https://doi.org/10.1177/0146167211408329

Hofstee, W., \& Berge, J. (2004). Personality in proportion: A Bipolar proportional scale for personality assessments and its consequences for trait structure. Journal of Personality Assessment, 83, 120-127. https://doi.org/10.1207/s15327752jpa8302_04

Köllner, M. G., \& Schultheiss, O. C. (2014). Meta-analytic evidence of low convergence between implicit and explicit measures of the needs for achievement, affiliation, and power. Frontiers in Psychology, 5, 826. https://doi.org/10.3389/fpsyg.2014.00826

Krohne, H. W., Egloff, B., Kohlmann, C.-W., \& Tausch, A. (1996). Untersuchungen mit einer deutschen Version der "Positive and Negative Affect Schedule" (PANAS). [Investigations with a German version of the Positive and Negative Affect Schedule (PANAS).]. Diagnostica, 42, 139-156.

Lang, J. W.B., \& Fries, S. (2006). A revised 10-item version of the Achievement Motives Scale. European Journal of Psychological Assessment, 22, 216-224. https://doi.org/10.1027/1015-5759.22.3.216

McClelland, D. C. (1985). Human motivation. Glenview, Ill.: Scott, Foresman.

Mehl, M. R., \& Conner, T. S. (Eds.). (2012). Handbook of research methods for studying daily life. New York: Guilford Press.

Mischel, W., Shoda, Y., \& Mendoza-Denton, R. (2002). Situation-behavior profiles as a locus of consistency in personality. Current Directions in Psychological Science, 11, 5054. https://doi.org/10.1111/1467-8721.00166 
Molenaar, P. C. M. (2004). A manifesto on psychology as idiographic science: Bringing the person back into scientific psychology, this time forever. Measurement: Interdisciplinary Research \& Perspective, 2, 201-218. https://doi.org/10.1207/s15366359mea0204_1

Neubauer, A. B., Lerche, V., \& Voss, A. (2018). Interindividual differences in the intraindividual association of competence and well-being: Combining experimental and intensive longitudinal designs. Journal of Personality, 86, 698-713. https://doi.org/10.1111/jopy.12351

Neubauer, A. B., Scott, S. B., Sliwinski, M. J., \& Smyth, J. M. (2019). How was your day? Convergence of aggregated momentary and retrospective end-of-day affect ratings across the adult life span. Journal of Personality and Social Psychology. Advance online publication. https://doi.org/10.1037/pspp0000248

Neubauer, A. B., Voelkle, M. C., Voss, A., \& Mertens, U. K. (2020). Estimating reliability of within-person couplings in a multilevel framework. Journal of Personality Assessment, 102, 10-21. https://doi.org/10.1080/00223891.2018.1521418

Neubauer, A. B., \& Voss, A. (2016). Validation and revision of a German version of the Balanced Measure of Psychological Needs Scale. Journal of Individual Differences, 37, 56-72. https://doi.org/10.1027/1614-0001/a000188

Neubauer, A. B., \& Voss, A. (2018). The structure of need fulfillment: Separating need satisfaction and dissatisfaction on between- and within-person level. European Journal of Psychological Assessment, 34, 220-228. https://doi.org/10.1027/1015-5759/a000326

Pinheiro, J., Bates, D., DebRoy, S., Sarkar, D., \& R. Development Core Team. (2018). nlme: Linear and nonlinear mixed effects models $R$. package version 3.1-137.

Rammstedt, B., \& John, O. P. (2005). Kurzversion des Big Five Inventory (BFI-K). Diagnostica, 51, 195-206. https://doi.org/10.1026/0012-1924.51.4.195 
Redelmeier, D. A., Katz, J., \& Kahneman, D. (2003). Memories of colonoscopy: A randomized trial. Pain, 104, 187-194. https://doi.org/10.1016/S0304-3959(03)00003-4

Reis, H. T., Sheldon, K. M., Gable, S. L., Roscoe, J., \& Ryan, R. M. (2000). Daily wellbeing: The role of autonomy, competence, and relatedness. Personality and Social Psychology Bulletin, 26, 419-435. https://doi.org/10.1177/0146167200266002

Robinson, M. D., \& Clore, G. L. (2002). Belief and feeling: Evidence for an accessibility model of emotional self-report. Psychological Bulletin, 128, 934-960.

Röcke, C., Hoppmann, C. A., \& Klumb, P. L. (2011). Correspondence between retrospective and momentary ratings of positive and negative affect in old age: Findings from a oneyear measurement burst design. The Journals of Gerontology. Series B, Psychological Sciences and Social Sciences, 66, 411-415. https://doi.org/10.1093/geronb/gbr024

Ryan, R. M., \& Deci, E. L. (2017). Self-determination theory: Basic psychological needs in motivation, development, and wellness. New York, London: Guilford Press.

Ryan, R. M., Soenens, B., \& Vansteenkiste, M. (2019). Reflections on self-determination theory as an organizing framework for personality psychology: Interfaces, integrations, issues, and unfinished business. Journal of Personality, 87, 115-145. https://doi.org/10.1111/jopy.12440

Schmalt, H.-D., Sokolowski, K., \& Langens, T. A. (2010). Das Multi-Motiv-Gitter für Anschluß, Leistung und Macht (MMG) [The Multi-Motive Grid for affiliation, achievement, and power] (2nd Ed.). Frankfurt am Main: Pearson.

Schüler, J., Baumann, N., Chasiotis, A., Bender, M., \& Baum, I. (2019). Implicit motives and basic psychological needs. Journal of Personality, 87, 37-55. https://doi.org/10.1111/jopy.12431

Schüler, J., Brandstätter, V., \& Sheldon, K. M. (2013). Do implicit motives and basic psychological needs interact to predict well-being and flow? Testing a universal 
hypothesis and a matching hypothesis. Motivation and Emotion, 37, 480-495. https://doi.org/10.1007/s11031-012-9317-2

Sheldon, K. M., Elliot, A. J., Kim, Y., \& Kasser, T. (2001). What is satisfying about satisfying events? Testing 10 candidate psychological needs. Journal of Personality and Social Psychology, 80, 325-339.

Sheldon, K. M., \& Hilpert, J. C. (2012). The balanced measure of psychological needs (BMPN) scale: An alternative domain general measure of need satisfaction. Motivation and Emotion, 36, 439-451. https://doi.org/10.1007/s11031-012-9279-4

Sheldon, K. M., \& Schüler, J. (2011). Wanting, having, and needing: integrating motive disposition theory and self-determination theory. Journal of Personality and Social Psychology, 101, 1106-1123. https://doi.org/10.1037/a0024952

Sokolowski, K., Schmalt, H. D., Langens, T. A., \& Puca, R. M. (2000). Assessing achievement, affiliation, and power motives all at once: the Multi-Motive Grid (MMG). Journal of Personality Assessment, 74, 126-145. https://doi.org/10.1207/S15327752JPA740109

Thompson, E. R. (2007). Development and Validation of an Internationally Reliable ShortForm of the Positive and Negative Affect Schedule (PANAS). Journal of Cross-Cultural Psychology, 38, 227-242. https://doi.org/10.1177/0022022106297301

Tóth-Király, I., Morin, A. J. S., Bőthe, B., Orosz, G., \& Rigó, A. (2017). Investigating the multidimensionality of need fulfillment: A bifactor exploratory structural equation modeling representation. Structural Equation Modeling: A Multidisciplinary Journal, 25, 267-286. https://doi.org/10.1080/10705511.2017.1374867

Van Assche, J., Van der Kaap-Deeder, J., Audenaert, E., Schryver, M. de, \& Vansteenkiste, M. (2018). Are the benefits of autonomy satisfaction and the costs of autonomy frustration 
dependent on individuals' autonomy strength? Journal of Personality, 86, 1017-1036. https://doi.org/10.1111/jopy.12372

Van der Kaap-Deeder, J., Vansteenkiste, M., Soenens, B., \& Mabbe, E. (2017). Children's daily well-being: The role of mothers', teachers', and siblings' autonomy support and psychological control. Developmental Psychology, 53, 237-251. https://doi.org/10.1037/dev0000218

Vansteenkiste, M., \& Ryan, R. M. (2013). On psychological growth and vulnerability: Basic psychological need satisfaction and need frustration as a unifying principle. Journal of Psychotherapy Integration, 23, 263-280. https://doi.org/10.1037/a0032359

Voelkle, M. C., Brose, A., Schmiedek, F., \& Lindenberger, U. (2014). Toward a unified framework for the study of between-person and within-person structures: Building a bridge between two research paradigms. Multivariate Behavioral Research, 49, 193-213. https://doi.org/10.1080/00273171.2014.889593

Wang, L. P., \& Maxwell, S. E. (2015). On disaggregating between-person and within-person effects with longitudinal data using multilevel models. Psychological Methods, 20, 63-83. https://doi.org/10.1037/met0000030

Wilson, T. D., \& Gilbert, D. T. (2016). Affective forecasting. Current Directions in Psychological Science, 14, 131-134. https://doi.org/10.1111/j.0963-7214.2005.00355.x Wirtz, D., Kruger, J., Napa Scollon, C., \& Diener, E. (2003). What to do on spring break? The role of predicted, on-line, and remembered experience in future choice. Psychological Science, 14, 520-524. https://doi.org/10.1111/1467-9280.03455 
Table 1

Model Fit of the Four Competing Measurement Models for the Perceived Need Effect Scales.

\begin{tabular}{|c|c|c|c|c|c|c|c|c|}
\hline Model & $\chi^{2}$ & $\mathrm{c}$ & $\mathrm{df}$ & CFI & RMSEA $^{\mathrm{a}}$ & SRMR & $\mathrm{AIC}$ & $\mathrm{BIC}$ \\
\hline & \multicolumn{8}{|c|}{ Study 1} \\
\hline Model 1 & 684.105 & 1.037 & 135 & .243 & $.151[.140 ; .162]$ & .154 & 9436.220 & 9608.339 \\
\hline Model 2 & 402.401 & 1.072 & 134 & .630 & $.106[.094 ; .118]$ & .092 & 9159.825 & 9335.132 \\
\hline Model 3 & 497.989 & 1.083 & 132 & .496 & $.124[.113 ; .136]$ & .124 & 9271.700 & 9453.381 \\
\hline Model 4 & 184.634 & 1.065 & 120 & .911 & $.055[.038 ; .070]$ & .063 & 8953.115 & 9173.045 \\
\hline Model 1 & 2752.189 & 1.214 & 135 & .471 & $.133[.128 ; .137]$ & .132 & 61476.632 & 61746.896 \\
\hline Model 2 & 1518.678 & 1.136 & 134 & .720 & $.097[.092 ; .101]$ & .074 & 59863.473 & 60138.741 \\
\hline Model 3 & 2728.794 & 1.153 & 132 & .475 & $.134[.129 ; .138]$ & .149 & 61287.849 & 61573.128 \\
\hline Model 4 & 412.612 & 1.171 & 120 & .941 & $.047[.042 ; .052]$ & .041 & 58649.078 & 58994.415 \\
\hline
\end{tabular}

Note. $\mathrm{c}=$ scaling factor; $\mathrm{df}=$ degrees of freedom; $\mathrm{CFI}=$ comparative fit index; RMSEA = root mean square error of approximation; $\mathrm{SRMR}=$ standardized root mean square residual; AIC = Akaike Information Criterion; BIC = Bayesian Information Criterion. The best fitting model in each study is marked in bold face.

a: $90 \%$ confidence interval in brackets. 
Table 2

Correlations of Need Effect Subscales with Other Person-Level Variables.

\begin{tabular}{|c|c|c|c|c|c|c|c|}
\hline \multirow[t]{3}{*}{ Contruct } & \multicolumn{6}{|c|}{ Need Effect } & \multirow[t]{2}{*}{ Mean $(S D)$} \\
\hline & Aut_s & Com_s & Rel_s & Aut_f & Com & Rel_f & \\
\hline & \multicolumn{6}{|c|}{ Study 1} & \\
\hline Implicit Hope of Power (MMG) & .11 & .07 & -.05 & .10 & .10 & .10 & $7.85(2.53)$ \\
\hline Implicit Fear of Power (MMG) & .10 & .02 & .02 & .09 & $.23 * *$ & .14 & $7.63(2.46)$ \\
\hline Implicit Hope of Affiliation (MMG) & .07 & .06 & -.08 & .09 & .00 & .03 & $5.73(2.15)$ \\
\hline Implicit Fear of Rejection (MMG) & -.02 & -.04 & -.01 & .01 & $.20 *$ & .11 & $6.54(2.57)$ \\
\hline Implicit Hope of Success (MMG) & $.16^{*}$ & .13 & -.09 & .07 & -.06 & -.01 & $6.79(2.39)$ \\
\hline Implicit Fear of Failure (MMG) & .01 & -.07 & -.02 & .07 & .12 & .11 & $4.41(2.36)$ \\
\hline Explicit Hope of Success (AMS) & .11 & .15 & $.17^{*}$ & -.11 & -.07 & .00 & $3.25(0.44)$ \\
\hline Explicit Fear of Failure (AMS) & $-.26 * *$ & .06 & -.08 & .15 & $.53 * *$ & $.27 * *$ & $2.61(0.65)$ \\
\hline Internal consistency (Cronbach's $\alpha$ ) & .67 & .76 & .75 & .57 & .67 & .73 & \\
\hline \multirow[t]{3}{*}{ Mean $(S D)$} & 6.18 & 6.49 & 6.59 & 4.97 & 5.23 & 5.69 & \\
\hline & $(0.75)$ & $(0.57)$ & $(0.59)$ & $(1.16)$ & $(1.23)$ & $(1.13)$ & \\
\hline & \multicolumn{6}{|c|}{ Study 2} & \\
\hline Extraversion & $.15^{* *}$ & $.16^{* *}$ & $.27 * *$ & $-.11 * *$ & $-.12 * *$ & $-.06^{*}$ & $3.56(0.90)$ \\
\hline Neuroticism & .00 & .00 & -.01 & $.31 * *$ & $.42 * *$ & $.34 * *$ & $2.93(0.87)$ \\
\hline Agreeableness & .04 & .01 & $.18^{* *}$ & $-.09 * *$ & $-.11 * *$ & .01 & $3.36(0.81)$ \\
\hline Conscientiousness & $.14^{* *}$ & $.22 * *$ & $.16^{* *}$ & $-.10 * *$ & -.05 & -.02 & $3.72(0.73)$ \\
\hline Openness & $.33 * *$ & $.22 * *$ & $.19 * *$ & .04 & -.02 & .00 & $4.29(0.58)$ \\
\hline Life Satisfaction & $.08 *$ & $.14 * *$ & $.15^{* *}$ & $-.17 * *$ & $-.18 * *$ & $-.09 * *$ & $5.29(1.17)$ \\
\hline Mean Positive Affect (Daily) & $.16^{* *}$ & $.15^{* *}$ & $.15 * *$ & $-.08 *$ & $-.14 * *$ & $-.13 * *$ & $3.56(0.56)$ \\
\hline Mean Negative Affect (Daily) & $-.06 *$ & $-.07 *$ & $-.08 *$ & $.12 * *$ & $.29 * *$ & $.21 * *$ & $1.51(0.44)$ \\
\hline Mean Autonomy Satisfaction (Daily) & $.19 * *$ & $.18 * *$ & $.18 * *$ & $-.06 *$ & $-.16^{* *}$ & $-.07 *$ & $5.08(0.80)$ \\
\hline Mean Competence Satisfaction (Daily) & $.18^{* *}$ & $.13^{* *}$ & $.08^{*}$ & -.03 & $-.10 * *$ & $-.07 *$ & $3.93(0.92)$ \\
\hline Mean Relatedness Satisfaction (Daily) & $.15^{* *}$ & $.21 * *$ & $.31 * *$ & -.02 & $-.07 *$ & -.01 & $5.51(0.87)$ \\
\hline Mean Autonomy Frustration (Daily) & -.04 & -.02 & -.05 & .06 & $.19 * *$ & $.16^{* *}$ & $2.45(0.92)$ \\
\hline Mean Competence Frustration (Daily) & $-.09 * *$ & $-.09 * *$ & $-.10 * *$ & $.11 * *$ & $.29 * *$ & $.18 * *$ & $2.31(0.83)$ \\
\hline
\end{tabular}




\begin{tabular}{llllllll} 
Mean Relatedness Frustration (Daily) & -.01 & $-.08^{* *}$ & $-.11^{* *}$ & $.09 * *$ & $.15^{* *}$ & $.10^{* *}$ & $1.92(0.75)$ \\
Internal consistency (Cronbach's $\alpha)$ & .59 & .79 & .80 & .62 & .69 & .80 & \\
Mean $(S D)$ & 6.12 & 6.32 & 6.40 & 4.88 & 5.08 & 5.61 \\
& $(0.82)$ & $(0.77)$ & $(0.75)$ & $(1.23)$ & $(1.30)$ & $(1.25)$ \\
\hline
\end{tabular}

Note. Table depicts means and standard deviations of the six need effect scales and other person level variables, as well as the correlations of the six need effect scales with other person level variables assessed in Study 1 (upper panel) and Study 2 (lower panel). In Study 2, mean scores in positive affect, negative affect, and the six need fulfillment scales were computed from all daily observations of a participant. MMG $=$ Multi Motive Grid; AMS = Achievement Motive Scale; Aut = Autonomy; Com = Competence; Rel = Relatedness; _ $\mathrm{s}=$ Satisfaction; $\_$f = Frustration . $N=179($ Study 1$) ; N=1,102($ Study 2$) .{ }^{*} p<.05,{ }^{* *} p<.001$. 
Table 3

Associations between Perceived Need Effects and Corresponding Experienced Need Effects.

\begin{tabular}{|c|c|c|c|c|}
\hline Predictor & Moderator & DV & $\begin{array}{r}\text { Cross-level } \\
\text { interaction }\end{array}$ & $R^{2}$ \\
\hline Autonomy satisfaction & Perceived autonomy satisfaction effect & Positive affect & $\begin{array}{l}0.008 \\
(0.011)\end{array}$ & $0.0 \%{ }^{\mathrm{a}}$ \\
\hline Competence satisfaction & Perceived competence satisfaction effect & Positive affect & $\begin{array}{l}-0.009 \\
(0.010)\end{array}$ & $0.1 \%$ \\
\hline Relatedness satisfaction & Perceived relatedness satisfaction effect & Positive affect & $\begin{array}{l}0.031^{*} \\
(0.012)\end{array}$ & $2.7 \%$ \\
\hline Autonomy frustration & Perceived autonomy frustration effect & Negative affect & $\begin{array}{l}0.011^{*} \\
(0.005)\end{array}$ & $0.5 \%$ \\
\hline Competence frustration & Perceived competence frustration effec & Negative affect & $\begin{array}{c}0.018^{* *} \\
(0.005)\end{array}$ & $1.9 \%$ \\
\hline Relatedness frustration & Perceived relatedness frustration effect & Negative affect & $\begin{array}{l}0.015^{*} \\
(0.006)\end{array}$ & $0.2 \%$ \\
\hline
\end{tabular}

Note. Table depicts unstandardized regression coefficient (standard error in parentheses) representing the moderation of the within-person effect by the corresponding perceived need effect. $R^{2}$ represents the amount of reduction of the random slope variance after adding the interaction of the moderator and the within-person predictor; this has been estimated as pseudo- $R^{2}=1-v_{1}^{2} / v_{1,0}^{2}$ where $v_{1}^{2}$ is the random slope variance in a model including the interaction, and $v_{1,0}^{2}$ is the random slope variance in a model without the interaction.

$N=1,102 .{ }^{a} R^{2}$ estimate was negative. ${ }^{*} p<.05, * * p<.001$. 
Study 1

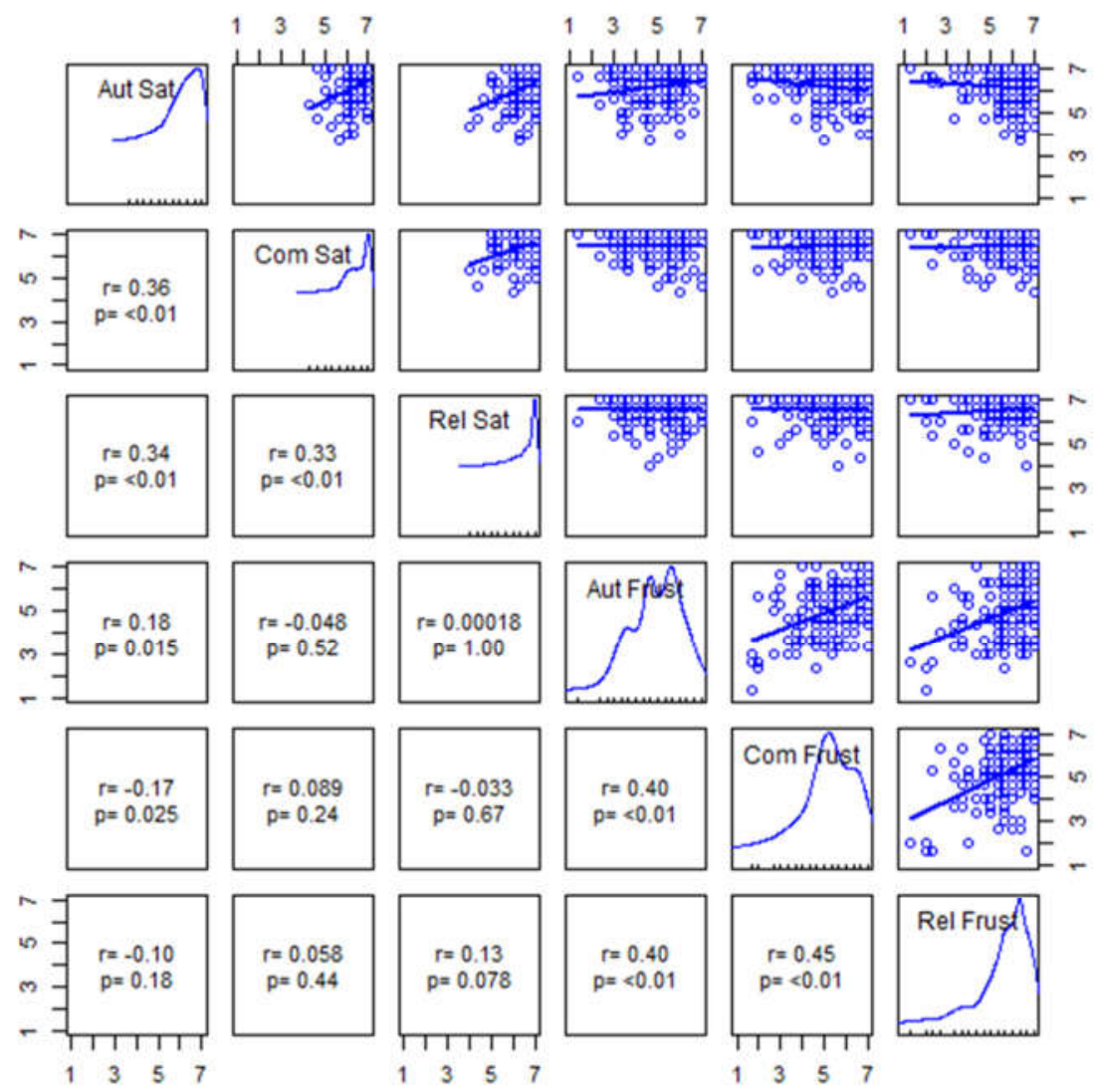

Study 2

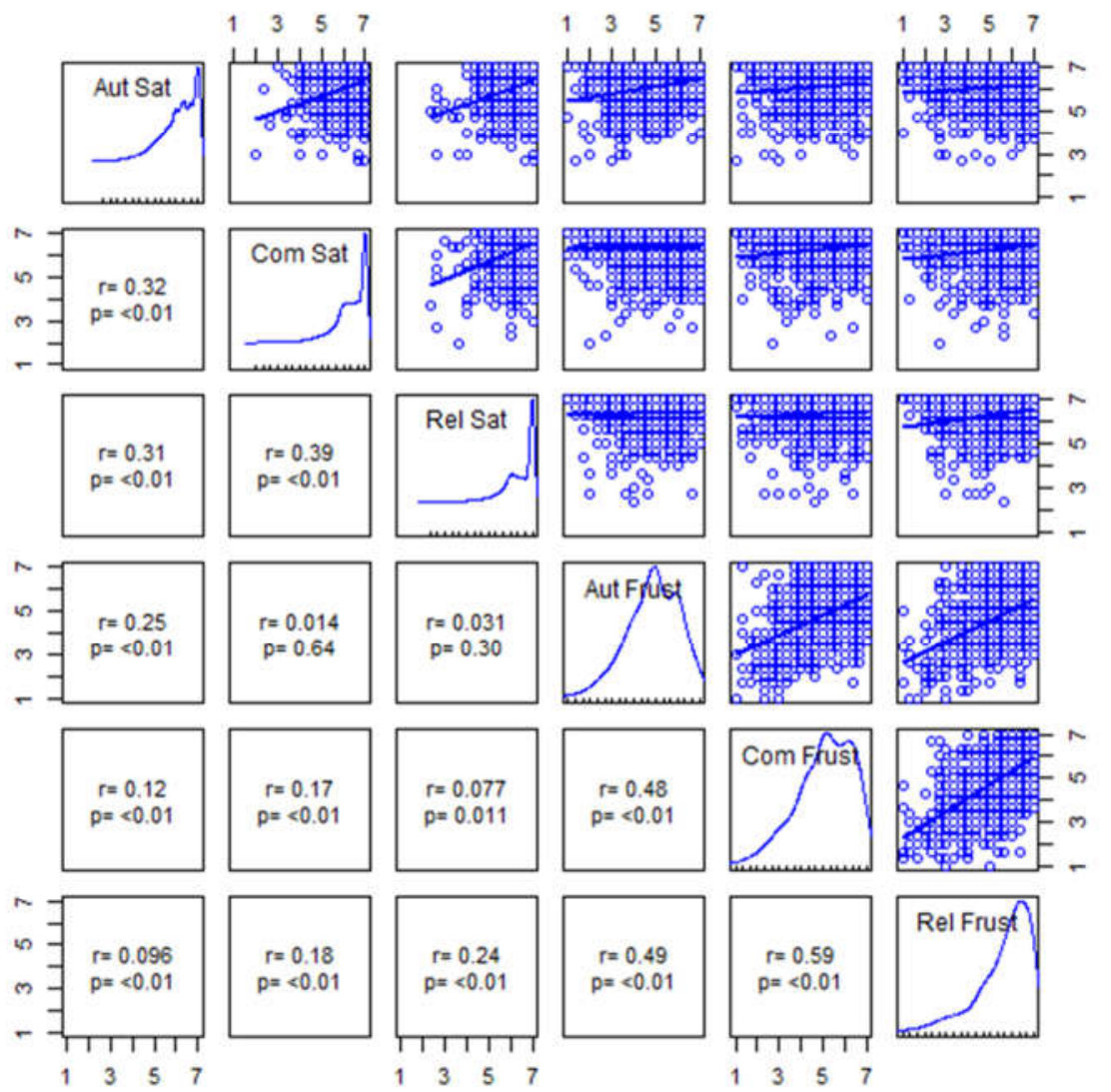

Figure 1. Density plot (diagonal), scatterplot (upper diagonal), and bivariate correlations (lower diagonal) of the six need effect subscales in Study 1 (left panel) and Study 2 (right panel). Aut = autonomy; Com = competence; Rel = relatedness; Sat $=$ satisfaction; Frust $=$ Frustration . $N=179($ Study 1$) ; N=1,102($ Study 2$)$. 

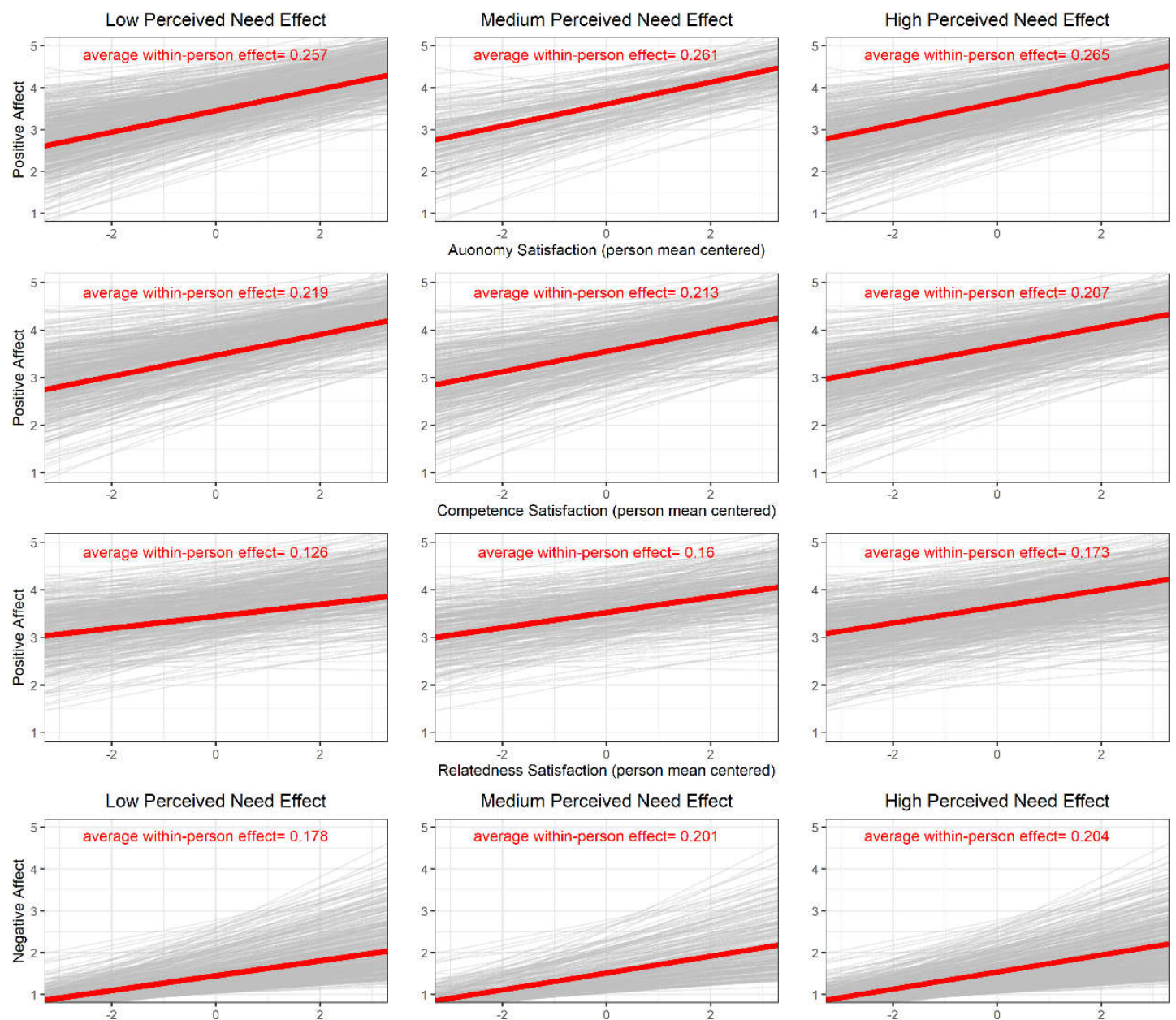

Medium Perceived Need Effect
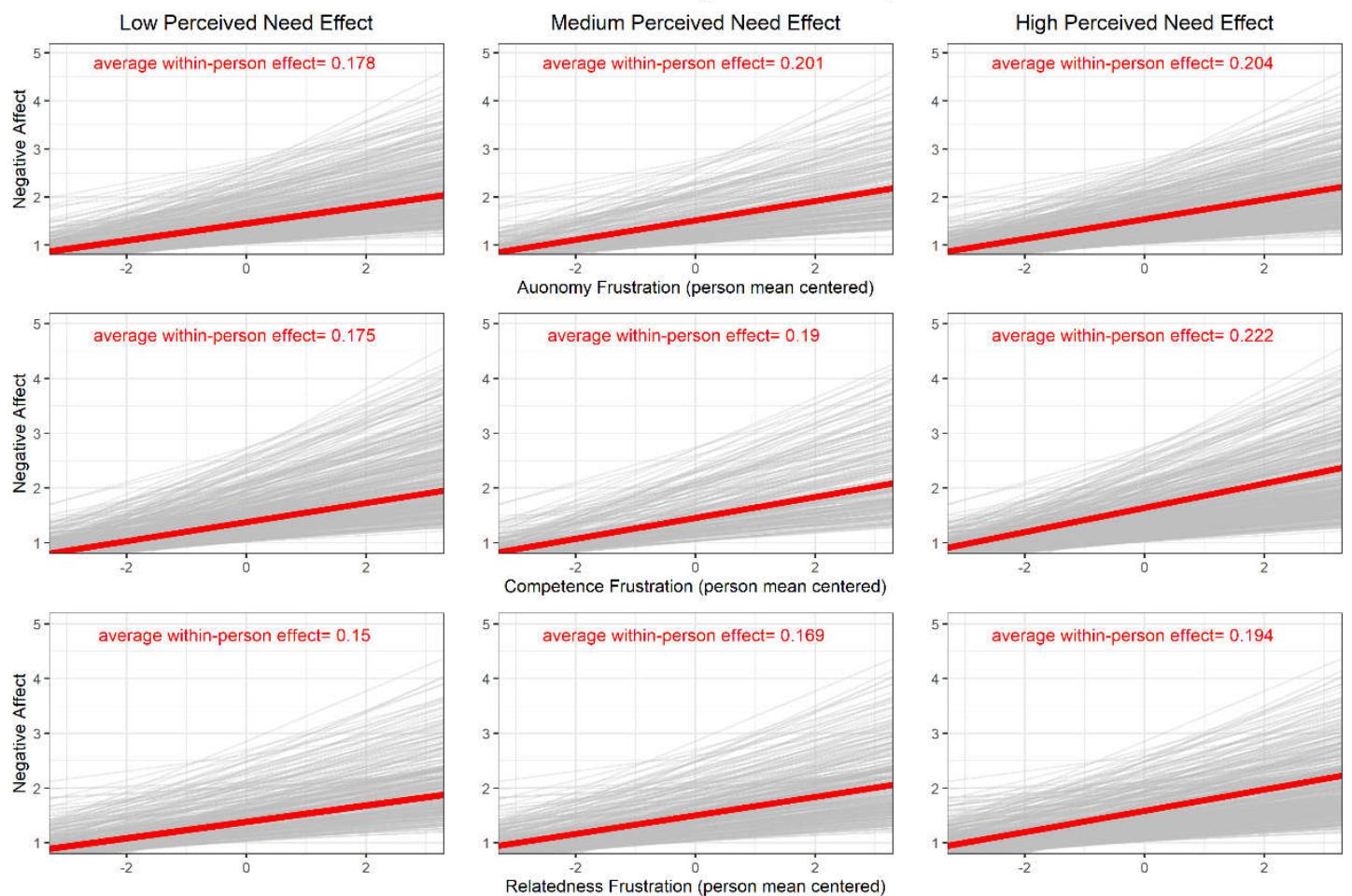

Figure 2. Associations of need satisfaction/frustration with positive/negative affect. The figures depicts predictions for each individual (grey lines), as well as the average withinperson association by level of perceived need effect (red lines). Participants were separated into three groups (low, medium, and high perceived need effect) via tertial splits. Upper panel depicts the association between daily need satisfaction and positive affect; lower panel shows the association between daily need frustration and negative affect. 